\title{
Non-Risk Price Discrimination in Insurance: Market Outcomes and Public Policy
}

\author{
R. Guy Thomas \\ Mathematics, Statistics \& Actuarial Science, University of Kent, Canterbury, Kent CT2 7NF, U.K.
}

This paper considers price discrimination in insurance, defined as systematic price variations based on individual customer data but unrelated to those customers' expected losses or other marginal costs (sometimes characterised as "price optimisation"). An analysis is given of one type of price discrimination, "inertia pricing", where renewal prices are higher than prices for risk-equivalent new customers. The analysis suggests that the practice intensifies competition, leading to lower aggregate industry profits; customers in aggregate pay lower prices, but not all customers are better off; and the high level of switching between insurers is inefficient for society as a whole. Other forms of price discrimination may be more likely to increase aggregate industry profits. Some public policy issues relating to price discrimination in insurance are outlined, and possible policy responses by regulators are considered. It is suggested that competition will tend to lead to increased price discrimination over time, and that this may undermine public acceptance of traditional justifications for risk-related pricing.

The Geneva Papers (2012) 37, 27-46. doi:10.1057/gpp.2011.32

Keywords: price discrimination; price optimisation; inertia pricing; paying customers to switch

\section{Introduction}

Price discrimination is the practice of selling products with similar marginal costs at different prices to different customers. In an insurance context, this concept of "nonrisk" price discrimination does not include risk-related price variations, which reflect differences in expected marginal costs. In the past few years non-risk price discrimination has become increasingly prevalent in retail non-life insurance in many European countries; ${ }^{1}$ it is also starting to be applied in the U.S. ${ }^{2}$ Some industry observers estimate that around half the U.K. motor insurance market is now using some form of non-risk price discrimination. ${ }^{3}$ Case studies of early adopters claim profit improvements of 2-4 per cent of gross premiums, ${ }^{4}$ which are substantial relative to typical profit margins in many classes of insurance. This paper considers the consequences of such non-risk price discrimination for the insurance market as a whole. In what ways might an insurance

\footnotetext{
${ }^{1}$ Krikler et al. (2004); Anderson (2008); Tillinghast (2008).

2 Tillinghast (2007); Watson Wyatt (2007); EMB (2009).

${ }^{3}$ Personal communications.

${ }^{4}$ Earnix (2007).
} 
market in which price discrimination is widely practised differ from a market where pricing is mainly risk-based? What legal and reputational issues may act as constraints? How should regulators respond to the practice?

The concept of price discrimination has been used in economics for over 80 years. ${ }^{5}$ In the past three decades, price discrimination based on multivariate analyses of customer characteristics has become common for products such as airline passenger seats and hotel rooms. Contemporary practitioners often use the term "price optimisation", but from a public policy perspective it is not obvious that insurance prices with non-cost-based individual variations are optimal (although they may be); the well-established earlier terminology is more descriptive and remains universal in recent economics literature, where the term "discrimination" carries no negative connotation, so it will be used here.

Economists have traditionally referred to first-degree, second-degree and thirddegree price discrimination. ${ }^{6}$ For insurance, the most pertinent concept is third-degree price discrimination. This refers to situations where customers are at least to some degree identifiable before a price offer is made. So the firm can identify (at least probabilistically) different types of customers, based on their individual characteristics, and make offers at different prices to the different types of customers. For example, renewals are often distinguished from risk-identical new customers, with different (usually lower) price offers made to new customers - a practice referred to as inertia pricing ${ }^{7}$ or "paying customers to switch". ${ }^{8}$

Existing literature on non-risk price discrimination in insurance is sparse. A book by Robert Phillips ${ }^{9}$ gives a practitioner's account of price optimisation techniques, but particular features of insurance are not considered. Two previous case studies describe price optimisation in motor insurance from the perspective of single insurers in Israel ${ }^{10}$ and Italy. ${ }^{11}$ None of these considers overall market outcomes or public policy issues. There is a considerable economics literature analysing the public policy aspects of price discrimination in general, ${ }^{12}$ but this literature does not address particular features of insurance. This paper's contribution is to apply the analysis to retail insurance, a field in which price discrimination is now pervasive in some national markets, and yet largely unacknowledged in any existing literature.

The rest of the paper is structured as follows. The next section outlines the theory of price discrimination from the viewpoint of a single firm, with competitors' prices taken

\footnotetext{
${ }^{5}$ Pigou (1920); Robinson (1933).

${ }^{6}$ First-degree price discrimination is where all customers are charged the maximum prices they would be prepared to pay; this is never achievable in practice. Second-degree price discrimination is where the firm believes that demand elasticity varies by customer type, but cannot identify a customer's type before making a price offer; the firm therefore attempts to make customers self-select into elasticity types, by means such as advertising or price menus or bundling of goods. Third-degree price discrimination is where customers are at least to some degree identifiable before a price offer is made, so that different price offers can be made to different customers, as in the case of insurance.

${ }^{7}$ Faculty and Institute of Actuaries (2001).

${ }^{8}$ Chen (1997).

${ }^{9}$ Phillips (2005).

${ }^{10}$ Krikler et al. (2004).

${ }^{11}$ Barone and Bella (2004).

${ }^{12}$ Recent surveys are given by Armstrong (2006, 2008) and Stole (2007).
} 
as given. The paper then considers the economic impact of price discrimination in a competitive market on customers and firms in aggregate, focusing particularly on the example of inertia pricing. Legal and reputational issues are then considered, and public policy issues and possible responses by regulators are discussed. Throughout the rest of the paper, the term "price discrimination" is to be understood to mean nonrisk price discrimination; it does not include cost-based price variations based on differences in insureds' expected losses.

\section{Price discrimination by a single insurer}

This section outlines the theory of price discrimination from the viewpoint of a single insurer, with competitors' prices taken as a given. The effect of price discrimination on firms and customers in aggregate, which is our main interest in this paper, is deferred to the next section below.

We assume that the risks for which the insurer can sell policies are all mutually independent. ${ }^{13}$ In a competitive insurance market, each insurer's price for a risk can be seen as a bid for the customer's business. The probability of winning the bid when with a particular price is given by a bid-response function. The expected profit contribution if the insurer bids price $p$ is

$$
\pi(p)=\rho(p) \cdot(p-c)
$$

where $\rho(p)$ is the bid-response function $(0 \leqslant \rho(p) \leqslant 1)$ at price $p$, and $c$ is the insurer's expected marginal cost, so that $(p-c)$ is the expected profit contribution if the bid at price $p$ is successful.

Bid-response functions can be estimated by the insurer from data on the take-up of past quotations. Methods of estimating bid-response functions are discussed further in Appendix A.

What price should the insurer bid to maximise expected profit on a particular price quotation? Intuitively, the optimal price bid will depend on the customer's response to variations in price, that is the elasticity $\varepsilon$ of the customer's bid-response function. With a little algebra we can derive the following "mark-up" rule relating the bid-response elasticity $\varepsilon$ to the optimal bid:

$$
\frac{(p-c)}{p}=-\frac{1}{\varepsilon}
$$

that is, the profit-maximising "mark-up" fraction $(p-c) / p$ is inversely proportional to the corresponding bid-response elasticity $\varepsilon$. The profit-maximising price is

$$
p=\frac{c}{(1+1 / \varepsilon)}
$$

\footnotetext{
${ }^{13}$ This allows us to focus on a single risk as the unit of analysis. Expected profit for the whole firm is maximised by maximising expected profit on each risk.
} 
This formula maximises the expected profit contribution from a single price quotation. In practice, maximisation will generally be carried out on a portfolio basis, that is across the full rate schedule, by a constrained optimisation. Some constraints might reflect regulatory restrictions, such as no optimisation on forbidden categories of information (race, sex, etc.), or maximum loadings on risk prices. Other constraints might be imposed by management, such as local monotonicity in rating factors, minima for response rates (i.e. trade-off of market share against profit), maxima for changes from the existing rates, and consistency with any marketing messages. The prices from this optimisation can then be used to specify a rating schedule. Alternatively, where regulation permits individual variation in rates, the optimisation algorithm can be incorporated into point-of-sale quotation systems, so that a new optimisation is carried out for each quotation.

\section{Insurance compared with other markets}

The analysis outlined above can be applied wherever a supplier quotes a customised price in response to a customer request, and is not specific to insurance. Insurers have a number of advantages, and also one important potential disadvantage, relative to other firms in applying price discrimination. The advantages are better data, greater pricing opacity, and the infeasibility of customer arbitrage in insurance, which are considered further in the discussion of public policy later in the paper. The important potential disadvantage is the possibility of adverse selection. Customers who are higher risk for reasons known to them but not fully recognised in the insurer's risk rating may expect to face higher prices or have more difficulty in obtaining insurance elsewhere, and so be less responsive to non-risk price increases. This suggests the possibility that non-risk-related price increases might, in part, lead to the retention of a higher risk clientele. This may limit any advantage which insurers might obtain from non-risk price discrimination.

\section{Price discrimination and the whole market of insurers}

This section considers the economic impact of price discrimination in a competitive market on customers and insurers in aggregate. This section largely abstracts from considerations of fairness or reputation and public policy issues, which are considered in the next section.

An insurer will generally be better off if it can operate price discrimination, for given prices offered by its rivals. But once the effects of competition are taken into account, it is not obvious that price discrimination will benefit insurers in aggregate. Price discrimination increases competition for customers with high bid-response elasticities, because insurers can offer lower prices to attract these customers without giving up margin on customers with low elasticity. Under price discrimination the pricing pressure exerted by high-elasticity customers is no longer diffused across the firm's entire customer base.

\section{Inertia pricing: best-response asymmetry}

A common form of price discrimination in insurance is that prices for renewal of existing policies are increased, while introductory offers are made to attract new 
customers, a practice which has been called "inertia pricing"7 or "paying customers to switch". ${ }^{8}$ Similar practices can also be observed in other consumer financial markets, including credit cards and mortgages.

A number of economists have considered the effect of differential pricing to existing and new customers on prices and industry profits in equilibrium. There are two types of models. The first is where there are no switching costs but customers have different preferences for different firms' products, and past purchase histories enable firms to learn about these preferences; an example would be different satellite television services. ${ }^{14}$ The second type is where products are homogenous, but past purchasing decisions create switching costs for the customer. ${ }^{8}$ The latter type seems more relevant to insurance.

Switching costs are a monetary representation of the customer's time and hassle in moving to a new insurer compared with renewing an existing policy. Switching costs are higher for insurance than for many products because of the individualised nature of pricing. To compare prices, it is necessary to answer underwriting questions from each alternative insurer. Even with the most streamlined new business processes, this makes switching a more time-consuming (i.e. costly) action for the customer than for many products, where definitive alternative prices can generally be compared just by observing advertisements.

Applying a switching costs model (the details are given in Appendix B) suggests that inertia pricing in markets such as auto insurance where coverage is compulsory (or nearly compulsory) is likely to have the following effects:

(1) total welfare (the sum of insurer profits plus consumer surplus) is lower than under uniform pricing;

(2) aggregate insurer profits are lower than under uniform pricing;

(3) customers in aggregate are better off, but not all customers are better off; and

(4) firms with smaller market share gain relative to firms with larger market share.

Some intuition for these effects is given below. ${ }^{15}$

An intuitive explanation for total welfare being lower under inertia pricing is that inertia pricing leads to a higher level of switching. Because the model assumes insurance is compulsory or near-compulsory, output (number of insurance policies written) is the same under inertia pricing as under uniform pricing. Total welfare is

\footnotetext{
${ }^{14}$ Fudenberg and Tirole (2000).

${ }^{15}$ Some older insurance literature observes that loss ratios tend to be lower for policies of longer duration, and attributes this not to non-risk price discrimination but to an experience rating concept termed "lowballing" (Kunreuther and Pauly, 1985; D'Arcy and Doherty, 1990). This is where an insurer charges a first-year price based on an average of premiums for high and low risks. The insurer then observes information during the year which can be used to separate the insureds into high and low risks; the private information is not observable by competing insurers. In the second year, the insurer declines to renew the high risks, while renewing the low risks at a price which is lower than the first-year price, but does not give full credit for either the privately observed "good news" about their low risk, and so gives a higher profit margin on renewals than on new business. However, this explanation is not sufficient to account for renewal prices which are higher than the contemporaneous price for a new customer approaching the firm, as in the case of inertia pricing.
} 
then wholly determined by switching costs: a higher level of switching costs is a deadweight cost on society as a whole, implying lower total welfare.

Does this welfare loss fall on insurers in the form of lower aggregate profits, or could it be shifted wholly to customers in the form of higher average prices? An intuitive explanation for why it must fall at least partly on insurers is the concept of bestresponse asymmetry. ${ }^{16}$ Best-response asymmetry is where firms disagree on which customers have elastic and inelastic demand. Inertia pricing is based on best-response asymmetry: each firm faces less elastic demand from its own customers (because a fraction of them will renew without investigating alternative price quotations), and more elastic demand from other firms' customers (because any customer considering a switch at renewal will generally be comparing at least two price quotations). Under these conditions, price discrimination tends to intensify competition for all customers, and so reduces aggregate industry profits.

Although aggregate industry profits are lower under inertia pricing, not all customers are better off. Prices are lower than under uniform pricing for customers who switch, but higher for those who do not switch. The cost of switching to the customer varies depending on the valuation they place on their own time. Customers with low switching costs benefit by switching frequently under inertia pricing; customers with high switching costs are better off under uniform pricing.

An intuitive explanation for firms with smaller market share benefiting relative to firms with larger market share is that the practice of "paying customers to switch" enables smaller firms to compete despite the economies of scale of larger firms. ${ }^{17}$

\section{Other forms of price discrimination: best-response symmetry}

The analysis summarised above suggests that inertia pricing represents a prisoner's dilemma for insurers. Any firm can gain a temporary advantage by paying the customers of its rivals to switch, but in the long term the practice reduces aggregate industry profits. This result arises from the specific features of inertia pricing, in particular bestresponse asymmetry.

The converse of best-response asymmetry is best-response symmetry, where all firms agree on which customers have elastic and inelastic demand. For example, perhaps older customers are believed to have less elastic demand than younger customers. Under best-response symmetry, older customers will face higher prices from all firms, and younger customers lower prices, than under uniform pricing. Price discrimination based on best-response symmetry will not intensify competition for all customers, and so may be more likely to increase aggregate industry profits, making customers in aggregate worse off.

In practice, insurance price optimisation is often based on multivariate models, rather than a single factor such as past purchasing history or age. The preceding observations suggest the conjecture that insurers might gain more durable advantage from

\footnotetext{
${ }^{16}$ Corts (1998).

${ }^{17}$ For evidence of the existence of economies of scale in non-life insurance, see Hirao and Inoue (2004) for Japan; Praetz (1980) for the U.S.; and Doherty (1981) for Canada.
} 
focusing discrimination on characteristics such as age or gender, which are the same from the viewpoint of all insurers (best-response symmetry), rather than paying customers to switch (best-response asymmetry).

\section{Reputational and legal issues}

The analysis above suggests that price discrimination can sometimes benefit customers in aggregate. Nevertheless price discrimination tends to be regarded with suspicion by customers and sometimes by the law. There is a long history of such concerns in various markets.

\section{Consumer attitudes}

Both casual observation and a number of experimental investigations suggest that price discrimination is often disliked by customers. For example, in September 2000, Amazon was found to be selling some items at prices up to 40 per cent higher for some customers than for others, based on the customers' purchasing histories. Amazon paid compensation to 6,896 customers, and stated that it would not discriminate in this way again. $^{18}$

This perception that price discrimination is unpopular seems to be shared by many of the proponents of price discrimination. One illustration of this is that vendors of banking and insurance price optimisation software report that "most of our customers have kept their investment in pricing optimisation technology quiet". ${ }^{19}$ According to another banking industry analyst, "There is a consistent belief that if word gets out to the press, users of price-optimisation software will be deemed users of price-gouging software". 20

What is the nature of customers' objection to price discrimination? People tend to object to practices which penalise loyalty, such as inflated prices for renewal of contracts. They tend not to object to loyalty discounts. ${ }^{21}$ Variations based on time of purchase seem to be more acceptable than variations based on buyer identification. ${ }^{22}$ Discounts for older people seem to attract little controversy, whether operated by businesses (e.g. reduced rail and coach fares in many European countries) or government (e.g. in the United Kingdom, free television licenses for persons over 75). Discounts for young people also seem to be accepted: again, reduced rail and coach fares are common, and also reduced subscriptions in many membership organisations such as sports and other clubs. Insurance prices often vary with age in a U-shaped pattern which manages to offend both these age-related norms. Furthermore, inertia pricing may exploit lower financial literacy or confidence among older customers, which again offends the norm of special respect or discounts for elderly people.

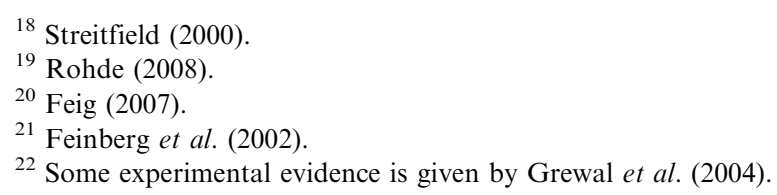




\section{Legal constraints}

Legal constraints on price discrimination include insurance price regulation, equal treatment laws and antitrust laws.

Some jurisdictions, including many states of the U.S., require pre-filing of rates with a regulator, with the rates required not to be excessive, inadequate or unfairly discriminatory. Requirements such as these may make price discrimination more difficult to implement. In some cases non-risk variations by insurance rating class may be permitted, but not non-risk variations at the level of individual policies.

Laws prohibiting discrimination by particular characteristics such as age or disability often contain exceptions for insurance underwriting, but these exemptions usually apply only to differences which are justified by differences in risk. ${ }^{23}$ In principle the prohibited characteristics can easily be excluded from any optimisation used to set prices. However, any suggestion of residual non-risk discrimination on the prohibited categories is likely to attract controversy, and may call into question the justification for the insurance exemptions from equal treatment laws. This is discussed further in the public policy section below.

Antitrust law is concerned with price discrimination because incumbent firms can sometimes use price discrimination strategically to make entry by new firms more difficult, and so reduce long-term competition. Price discrimination which has the effect of reducing competition may be illegal under article 82 of the EC Treaty in Europe, and the Robinson-Patman Act in the U.S. ${ }^{24}$ But this is not always pertinent, because some forms of price discrimination may increase competition.

\section{Possible public policy responses}

Public policy towards price discrimination is often ambivalent. On the one hand, economic analysis such as the inertia pricing example above suggests that price discrimination can sometimes benefit customers in aggregate. On the other hand, the analysis also suggests that inertia pricing generates socially wasteful excessive switching; and democratic governments are responsive to public perceptions of any unfairness in price discrimination. Furthermore, forms of price discrimination which involve bestresponse symmetry may be less favourable to customers than inertia pricing.

In considering regulatory policy, there are a number of further issues specific to insurance.

\section{Special issues in insurance markets}

(1) High power of insurers to discriminate: Insurers tend to have much greater power to discriminate than many other types of firm, for three reasons: better data, price opacity, and the infeasibility of arbitrage. As regards data, risk assessment means that insurers have a pretext to obtain much better data on their customers than other types

\footnotetext{
${ }^{23}$ For example in the U.K., the Disability Discrimination Act, and the Equality Act 2010.

${ }^{24}$ Chen (2005).
} 
of firm, and its reliability is enhanced by the legal doctrine of utmost good faith, which encourages prospective customers to answer questions honestly. In other markets, the power of firms to discriminate is limited because prospective customers are often anonymous, or can strategically misrepresent their characteristics to the firm without fear of penalty. As regards price opacity, risk-related individual price variations in insurance make non-risk-related price discrimination more opaque, and hence more difficult for customers to identify and challenge than in other markets. As regards arbitrage, this is not possible in insurance, because contracts are specific to an individual. In this respect, insurance products are unlike products such as books or online subscription services, where resale between customers can often undermine price discrimination.

(2) Price discrimination in insurance does not facilitate new markets: For products where marginal costs are very low relative to fixed costs, a standard justification of price discrimination is that it may make feasible markets which would not otherwise exist. A simple example will illustrate this. Suppose a consultant has two potential customers for a report, with reservation prices of US\$700 and US\$1,000. Suppose that opportunity cost of writing the report is US\$1,500. If the same price has to be charged to each customer, the report will not be written. But if US\$650 can be charged to one customer and US\$950 to the other, the report gets written and everyone is better off. Real examples of this phenomenon include software, where reduced prices for schools and similar institutions often apply; academic journals which charge lower subscription rates to individuals than to libraries; and passenger airlines, where price discrimination can often facilitate opening a new route in a network. But in insurance, marginal costs are generally a significant proportion of total costs. Insurance is often compulsory or effectively compulsory, leaving little scope for expanding market size. Thus one of the arguments which may justify price discrimination in many markets has little application in insurance.

(3) Price discrimination may undermine utmost good faith: As noted in (1) above, insurers collect more information about their customers than most firms, and the law mandates customers to provide this information truthfully. The public policy rationale for this law, which is unique to insurance, is the presumed social benefit of accurate risk assessment. In many jurisdictions insurers are also permitted to share information for the purposes of preventing fraud, which public policy sanctions as an exception to wider antitrust policy. If information ostensibly gathered or shared for risk assessment or fraud prevention is used for other purposes, this may raise doubts about legitimacy, and over time this could undermine public acceptance of the doctrine of utmost good faith.

(4) Price discrimination may undermine justifications for risk-related pricing: Individualised insurance pricing is often controversial even when it reflects expected costs. Many people object to statistical discrimination by criteria such as sex or age. Laws in many countries ban such discrimination, but with exemptions for risk-related variations in insurance prices; these exemptions are often controversial and sometimes withdrawn, as for example in the recent judgement of the European Court of 
Justice. ${ }^{25}$ The main argument which insurers and insurance regulators have used to defend such exemptions is that permitting individualised price variations increases fairness by allowing insurers to reflect individual risks. The practice of systematic nonrisk-related individual price variations undermines this justification, and may weaken the credibility of insurers and insurance regulators who rely on it.

As an example of how non-risk price discrimination can impinge on arguments about the justification for risk-related pricing, consider the question of age-related pricing. Most types of personal insurance risk vary by age, and prices are normally differentiated to reflect this. Separately, price elasticity at renewal of personal insurance policies is generally reported to be lower for older people. ${ }^{26}$ This will probably also mean that the difference in price elasticity between potential renewals and potential new customers is larger at higher ages. Absent regulatory restrictions, a profit-maximising insurer will then have a larger differential between renewal prices and new customer prices for older customers than for younger customers. Many insurers in the United Kingdom appear to have followed this practice, ${ }^{27}$ which has hitherto not been unlawful. However, under the Equality Act 2010 a prohibition on age discrimination in the supply of goods and services will come into force in 2012. There will be an exception for the pricing of financial services, where this is a proportionate response to risks or costs associated with age. There are obvious tensions between the risk-related arguments which are used to justify insurers' exemption from the age discrimination law, the incentives for insurers to practice non-risk price discrimination, and the public belief that age discrimination should be restricted.

(5) Distributional effects of price discrimination: Even if customers in aggregate gain from price discrimination, distributional effects may be of concern to a regulator. Distributional effects arise because customers' price elasticities vary according to their wealth. The nature of this variation may be different in different markets. For example, for airlines and hotels, it seems plausible that price discrimination might often have progressive distributional effects: business demand is generally perceived as less elastic than leisure demand, and businesses might be seen as better able to afford higher prices than most individual customers. But in insurance, it seems plausible that price discrimination might often have regressive distributional effects. For example, financially sophisticated (usually richer) customers are generally perceived as more

${ }^{25}$ In March 2011, in the case of Association Belge des Consommateurs Test-Achats and Others vs. Conseil des ministres, the European Court of Justice ruled that risk-based gender variations in insurance prices would no longer be permitted for new policies sold in the European Union after 21 December 2012.

${ }^{26}$ In a logistic regression for renewal probability at one motor insurer, Krikler et al. (2004) report a statistically significant coefficient of 1.14 for logarithm of policyholder age. Israel (2005) reports that the probability of non-renewal of a motor insurance policy at one year's and five year's duration are 10 per cent and 6.5 per cent respectively, for one insurer in Georgia, U.S. But broken down by age, the corresponding non-renewal probabilities at one and five years are 11 per cent and 7 per cent for customers under age 55, and 8 per cent and 6 per cent for customers age 55 and over. Israel estimates that the differences between the one-year and five-year non-renewal rates is 75 per cent attributable to heterogeneity among customers (a selection effect), and only 25 per cent to a duration effect.

${ }^{27}$ For example, see Watson Wyatt (2009). 
likely to shop around, and so tend to benefit from price discrimination, while less financially sophisticated (usually poorer) customers tend to lose.

\section{Possible public policies}

Two main regulatory responses which could be considered by policymakers are bans on specific discriminatory practices, or better disclosure of practices which insurers might prefer to obscure.

A regulator could prevent all inertia pricing by prohibiting renewal premiums being in any way dependent on the customer's previous premium. However the analysis earlier in this paper suggests that this will probably not benefit customers in aggregate. Alternatively, a regulator could prevent other forms of non-risk price discrimination by banning discrimination on certain categories of information, such as age or disability. Because these categories of information involve best-response symmetry for insurers, restricting non-risk discrimination on them may be more likely to be beneficial to customers than restrictions on inertia pricing.

As regards better disclosure, for inertia pricing a regulator could require firms to show on renewal notices any monetary excess of the renewal premium above the premium for a new customer with identical risk characteristics. This seems a relatively simple intervention, and would counter the opacity of individualised insurance pricing. A regulator could also run information campaigns to make customers aware of the value of obtaining quotes from several insurers at each renewal. A regulator could also provide or accredit price comparison websites, or regulate such sites to improve the integrity of the comparisons. ${ }^{28}$ Interventions such as these may help to ensure that inertia pricing intensifies competition sufficiently that customers in aggregate gain from the practice. But they do nothing to solve the conundrum of excessive switching arising from an artefact of market structure, which is wasteful to society as a whole.

\section{Conclusion}

Price discrimination is beneficial to firms who adopt these measures early on, at least in the period before other firms respond; some case studies of early adopters claim profit improvements of 2-4 per cent of gross premiums. ${ }^{4}$ In the longer term, when price discrimination is widely adopted, it is not clear whether it will increase or decrease industry profits. The predicted result is sensitive to the exact nature of the discrimination: it may increase aggregate profits if it involves best-response symmetry (all firms agree about the categorisation of customers, e.g. older customers have less elastic demand), but may reduce aggregate industry profits if it involves best-response asymmetry (firms differ in the categorisation of customers, e.g. other firms' customers have more elastic demand).

\footnotetext{
${ }^{28}$ For example, the Financial Services Authority in the U.K. operates price comparison sites for mortgages and various investment products. It has also reviewed commercial price comparison sites for general insurance run by firms it regulates, and published a list of improvements which it expects these firms to make (FSA, 2008).
} 
In the model in this paper, inertia pricing involves best-response asymmetry, and reduces aggregate industry profits. Customers pay lower prices in aggregate, but not all customers are better off. The higher switching is socially wasteful, in the sense that it arises as an artefact of market structure, and does not reflect changing customer requirements or brand preferences.

Insurance differs from most other products in that even cost-based pricing is often controversial. This is because cost-based pricing in insurance involves individual discrimination which often conflicts with social norms, and therefore requires special exemptions from anti-discrimination laws. Insurers and insurance regulators generally justify this discrimination on the basis that it increases fairness. But if the public becomes more aware that insurers systematically vary individual prices in ways which are not risk-related, political acceptance of the fairness of exemptions for insurance pricing may be weakened.

Whether or not insurers collectively ultimately benefit from price discrimination, in the absence of regulation competitive pressures will force more and more insurers to adopt it. Although price discrimination can sometimes benefit customers in aggregate by intensifying competition, the public perception is often that it involves unfairness. It seems unlikely there will be an easy resolution of the conflicts between competitive pressure, economic efficiency and some degree of public disapproval.

\section{References}

Anderson, D. (2008) 'Personal lines pricing', Presentation to GIRO conference 2008, www.actuaries.org.uk. Armstrong, M. (2006) 'Recent developments in the economics of price discrimination', in R. Blundell, W.K. Newey, and T. Persson, (eds.) Advances in Economics and Econometrics: Theory and Applications. Ninth World Congress, Volume 2, Cambridge, U.K.: Cambridge University Press.

Armstrong, M. (2008) 'Price discrimination', in P. Buccirossi (ed.) Handbook of Antitrust Economics, Cambridge, U.S.: MIT Press.

Barone, G. and Bella, M. (2004) 'Price-elasticity based customer segmentation in the Italian auto insurance market', Journal of Targeting Measurement and Analysis for Marketing 13: 21-31.

Chen, Y. (1997) 'Paying customers to switch', Journal of Economics and Management Strategy 6(4): 877-897.

Chen, Y. (2005) 'Oligopoly discrimination by purchase history', in M. Bergman, (ed.) The Pros and Cons of Price discrimination, Stockholm: Swedish Competition Authority, pp. 101-130.

Corts, K.S. (1998) 'Third-degree price discrimination in oligopoly: All-out competition and strategic commitment', Rand Journal of Economics 29(2): 306-323.

D'Arcy, S.P. and Doherty, N.A. (1990) 'Adverse selection, private information and lowballing in insurance markets', Journal of Business 63(2): 145-164.

Doherty, N.A. (1981) 'The measurement of output and economies of scale in the property-liability insurance industry', Journal of Risk and Insurance 48(3): 390-402.

Earnix (2007) 'Case studies: Large direct broker; Global personal lines insurer; Large auto insurer', www.earnix.com.

EMB (2009) 'Optimisation for the US market', Casuality Actuarial Society, at www.casact.com.

Faculty and Institute of Actuaries (2001) Inertia pricing-actuarial profession briefing statement.

Feig, N. (2007) 'Price optimisation is catching on', Bank Systems \& Technology, 10 August 2007.

Feinberg, F.M., Krishna, A. and Zhang, Z.J. (2002) 'Do we care what others get? A behaviourist approach to targeted promotions', Journal of Marketing Research 39(3): 277-291.

FSA (2008) 'Review into general insurance comparison websites', www.fsa.gov.uk.

Fudenberg, D. and Tirole, J. (2000) 'Customer poaching and brand switching', RAND Journal of Economics 31(4): 634-657. 
Grewal, D., Hardesty, D.M. and Gopalkrishnan, R.I. (2004) 'The effects of buyer identification and purchase timing on consumers' perceptions of trust, price fairness, and repurchase intentions', Journal of Interactive Marketing 18(4): 87-100.

Hirao, Y. and Inoue, T. (2004) 'On the cost structure of the Japanese property-casualty insurance industry', Journal of Risk and Insurance 71(3): 501-530.

Israel, M. (2005) 'Tenure dependence in consumer-firm relationships: An empirical analysis of consumer departures from automobile insurance firms', RAND Journal of Economics 36(1): 165-192.

Krikler, S., Dolberger, D. and Eckel, J. (2004) 'Method and tools for insurance price and revenue optimisation', Journal of Financial Services Marketing 9(1): 68-79.

Kunreuther, H. and Pauly, M. (1985) 'Market equilibrium with private knowledge: An example', Journal of Public Economics 26(3): 269-288.

Phillips, R.L. (2005) Pricing and Revenue Optimisation, Stanford: Stanford University Press.

Pigou, A.C. (1920) The Economics of Welfare, $1^{\text {st }}$ edn. London: Macmillan.

Praetz, P. (1980) 'Returns to scale in the U.S. life insurance industry.' Journal of Risk and Insurance 47(3): 525-533.

Robinson, J. (1933) The Economics of Imperfect Competition, London: Macmillan.

Rohde, F. (2008) 'Impact of pricing optimisation on consumers', Nomis Solutions, at www.nomissolutions .com.

Rothwell, M., Chan, C., Colomb, Y., Farnworth, C., Fulcher, G., Garner, M., Goldby, A., Gosrani, V., Jewell, M., Jordan, T., Kelsall, J., Le Delliou-Viel, S., Lowe, R., Malattia, R., Smith, A. and Spedding, M. (2009) 'Winner's curse: The unmodelled impact of competition', Report of Institute of Actuaries Working Party, www.actuaries.org.uk.

Stole, L.A. (2007) 'Price discrimination and competition', in M. Armstrong and R. Porter (eds.) Handbook of Industrial Organisation, volume 3, Amsterdam: Elsevier, pp. 2211-2299.

Streitfield, D. (2000) 'On the web price tags blur: What you pay could depend on who you are', Washington Post, 27 September, p. Al.

Taylor, C.R. (2003) 'Supplier surfing: Competition and consumer behaviour in subscription markets', RAND Journal of Economics 34(2): 223-246.

Tillinghast (2007) 'Price optimisation: A potent weapon for innovative insurers', www.tillinghast.com.

Tillinghast (2008) 'Price optimisation for profit and growth', www.tillinghast.com.

Watson Wyatt (2007) 'Optimised pricing', Presentation to Casualty Actuaries Society 2007 Annual Meeting.

Watson Wyatt (2009) 'The equality bill and pricing', Insurance Matters, (October): 4-7.

\section{About the Author}

R. Guy Thomas is an actuary and investor, and an honorary lecturer at the University of Kent. He has published articles in academic journals covering actuarial mathematics, insurance economics, and taxation and investment.

\section{Appendix A}

\section{Estimation of bid-response functions}

In many European jurisdictions, bid-response functions can be estimated from "price tests" in which prices quoted to identical risks are varied randomly for a test period and the effects on individual customer responses observed. Regulation in other jurisdictions may prevent price tests, in which case bid-response functions must be estimated in other ways. For example, any change in rates represents a natural experiment in which the effect on customer responses can be observed. Information which would be discarded in risk pricing analyses can often be useful, if it is kept-for example, the prices quoted at renewal to policies which did not renew. Logistic 
regression can be used to estimate the effect of categorical rating factors such as age, sex, tenure, previous claims and other factors on the response, thus allowing a bidresponse function to be constructed for a quote with any combination of rating factors. That is, if $\rho$ is the probability of a bid succeeding, $p$ is the quoted price, $a$ is the regression intercept, and $X$ is the matrix of $n$ rating factors each with $m$ categories, the effect of the rating factors on the response is estimated by regressing $X$ on logit $(\rho)$

$$
\operatorname{logit}(\rho)=\ln \left(\frac{\rho}{1-\rho}\right)=a+b_{p} p+b X
$$

and then the bid-response function for a quote with any particular combination of rating factors $X_{c}$ can be constructed from-

$$
\rho(p)=\frac{1}{1+e^{-\left\{\hat{a}+\hat{b}_{p} p+\hat{b} X_{c}\right\}}} .
$$

For example, in a case study of motor insurance in Israel, the statistically significant explanatory variables for the response were positive effects from vehicle value, tenure and policyholder age, and negative effects from premium and change on prior year premium. ${ }^{10}$

\section{Appendix B}

\section{An analysis of inertia pricing}

The analysis which follows is based on an earlier paper $^{8}$ which considers discounts or cash-backs for new customers, but adapted to reflect an "inertia" increase in premiums for renewing customers, which seems to be the more common framing in insurance.

We assume an insurance market with two firms $A$ and $B$, with the entire market of customers market represented by a measure of 1 (i.e. if $A$ has a market share of 50 per cent this is represented as 0.5 ). Insurance is compulsory or effectively compulsory (e.g. third-party motor insurance in many jurisdictions), so every customer buys one unit of insurance from one firm in each period. To simplify the presentation, we will abstract from risk-related differentials, and assume that all customers have the same expected cost of claims, which is observable by both insurers. ${ }^{29}$

The expected marginal cost of supplying a policy is the same $c$ for both firms, and the prices charged by the two firms are $p_{A}$ and $p_{B}$, both at or above $c$. If a customer switches from one firm to the other he will incur a switching cost $s$, which represents the time and inconvenience to the customer of switching insurers. The $s$ for each consumer in each period is assumed to be an independent realisation of a random variable $S$ which is uniformly distributed on $[0, t]$ across the population. This can be thought of as reflecting random variation from year to year in the other demands on a customer's time and attention around the date of renewal.

\footnotetext{
${ }^{29}$ This can be related to the real world of heterogenous risks by viewing the analysis as applicable separately to each homogenous risk class.
} 
Consider a mature market where both firms $A$ and $B$ have already established market shares $\alpha$ and $\beta$ respectively in previous periods under uniform pricing, We use the following notation, for $i=A, B$

$p_{i}=$ firm $i$ 's price for new customers

$e_{i}=$ firm $i$ 's escalation of price its own previous customers (so firm $A$ 's previous customers pay $p_{A}+e_{A}$ if they stay with firm $A$, or $p_{B}$ if they switch to firm $B$ )

$n_{i j}=$ the proportion of customers who bought from firm $j$ in the previous period but buy from firm $i$ in the current period

At the date of renewal, a customer who previously bought from $A$ is indifferent between continuing to buy from $A$ and switching to $B$ if his switching cost $s$ is such that $p_{B}=p_{A}+e_{A}-s$.

Therefore the proportion of customers staying with $A, n_{A A}$, is given by

$$
n_{A A}=\alpha \int_{p_{A}-p_{B}+e_{A}}^{t} \frac{1}{t} d s=\alpha\left(1-\frac{p_{A}-p_{B}+e_{A}}{t}\right)
$$

and the fraction of customers switching away from firm $A$ to firm $B, n_{B A}$, is

$$
n_{B A}=\alpha\left(\frac{p_{A}-p_{B}+e_{A}}{t}\right)
$$

provided that the difference between the two firms' prices plus the inertial escalation falls within the range of possible switching costs, that is $0 \leqslant p_{A}-p_{B}+e_{A} \leqslant t$.

Similarly for firm $B$,

$$
n_{B B}=(1-\alpha)\left(1-\frac{p_{B}-p_{A}+e_{B}}{t}\right)
$$

and

$$
n_{A B}=(1-\alpha)\left(\frac{p_{B}-p_{A}+e_{B}}{t}\right)
$$

provided that $0 \leqslant p_{B}-p_{A}+e_{B} \leqslant t$.

Firm $A$ 's and firm $B$ 's profits in this period are, respectively,

$$
\begin{aligned}
\pi_{A}= & \alpha\left(p_{A}+e_{A}-c\right)\left(1-\frac{p_{A}-p_{B}+e_{A}}{t}\right) \\
& +\frac{(1-\alpha)}{t}\left(p_{A}-c\right)\left(p_{B}-p_{A}+e_{B}\right)
\end{aligned}
$$


and

$$
\begin{aligned}
\pi_{B}= & (1-\alpha)\left(p_{B}+e_{B}-c\right)\left(1-\frac{p_{B}-p_{A}+e_{B}}{t}\right) \\
& +\frac{\alpha}{t}\left(p_{B}-c\right)\left(p_{A}-p_{B}+e_{A}\right) .
\end{aligned}
$$

For a Nash equilibrium, we need a pair of $\left(p^{*}{ }_{A}, e^{*}{ }_{A}\right)$ and $\left(p^{*}{ }_{B}, e^{*}{ }_{B}\right)$ such that $\left(p^{*}{ }_{A}, e^{*}{ }_{A}\right)$ maximises $\pi_{A}$ given $\left(p^{*}{ }_{B}, e^{*}{ }_{B}\right)$, and $\left(p^{*}{ }_{B}, e^{*}{ }_{B}\right)$ maximises $\pi_{B}$ given $\left(p^{*}{ }_{A}, e^{*}{ }_{A}\right)$. Setting the partial derivatives of the two profit functions equal to zero gives

$$
\begin{aligned}
& \frac{\partial \pi_{A}}{\partial p_{A}}= 0 \Rightarrow \alpha\left(1-\frac{p_{A}-p_{B}+e_{A}}{t}\right)-\frac{\alpha}{t}\left(p_{A}+e_{A}-c\right) \\
&+\frac{(1-\alpha)}{t}\left(p_{B}-p_{A}+e_{B}\right)-\frac{(1-\alpha)}{t}\left(p_{A}-c\right)=0 \\
& \frac{\partial \pi_{A}}{\partial e_{A}}=0 \Rightarrow \alpha\left(1-\frac{p_{A}-p_{B}+e_{A}}{t}\right)-\frac{\alpha}{t}\left(p_{A}+e_{A}-c\right)=0
\end{aligned}
$$

Analogous equations can be derived for $\pi_{B}$. This system of equations has the following unique solution

$$
\begin{gathered}
p_{A}^{*}=p_{B}^{*}=c+\frac{1}{3} t, \\
e_{A}^{*}=e_{B}^{*}=\frac{1}{3} t
\end{gathered}
$$

and the second-order conditions for profit maximisation are also satisfied by these solutions.

That is, given switching costs uniformly distributed on $[0, t]$, customers who switch are charged a mark-up of one-third of the maximum switching cost $t$. Customers who do not switch are charged twice this mark-up.

Substituting the equilibrium prices and inertial increases (B.9) and (B.10) into (B.2) and (B.4), we obtain the proportions of customers of each firm who switch firms in equilibrium in each period-

$$
n_{B A}=\frac{\alpha}{3} \quad \text { and } \quad n_{A B}=\frac{(1-\alpha)}{3} .
$$

Thus one-third of all customers in the market switch firms in every period. This high level of switching is socially inefficient: it arises as an artefact of the market structure, not as a result of changing brand preferences, and so represents a deadweight loss to society. The market structure features which give rise to excessive switching are annual contracts, no brand preferences, and private non-verifiable switching costs which the 
customer can communicate only by actually switching. In equilibrium any consumer with a switching cost, $s<t / 3$ switches, so the expected deadweight loss per consumer is

$$
\int_{0}^{\frac{t}{3}} s \frac{1}{t} d s=\frac{t}{18}
$$

Substituting the equilibrium prices and inertial increases (B.9) and (B.10) into the profit equations (B.5) and (B.6), we obtain the equilibrium profits as

$$
\pi_{A}^{*}=\frac{t}{3}\left(\frac{1}{3}+\alpha\right)
$$

and

$$
\pi_{B}^{*}=\frac{t}{3}\left(\frac{4}{3}-\alpha\right)
$$

Comparison with uniform pricing

Under uniform pricing, we use the following notation, for firms $i=A, B-$

$p_{i}^{u}=$ firm $i$ 's price

$m_{i}^{u}=$ the proportion of customers who buy from firm $i$

$\pi_{i}^{u}=$ firm $i$ s profit

We initially assume that firm $A$ 's price is higher, $p_{A 2}^{u} \geqslant p_{B 2}^{u}$. A consumer belonging to firm $A$ 's market share $\alpha$ in the previous period is indifferent between sticking with $A$ and switching to $B$ if his switching cost $s$ is such that $p_{B}^{u}=p_{A}^{u}-s$.

Therefore the proportion of customers staying with $A$ under uniform pricing, $m_{A}$, is given by

$$
m_{A}^{u}=\alpha \int_{p_{A}^{u}-p_{B}^{u}}^{t} \frac{1}{t} d s=\alpha\left(1-\frac{p_{A}^{u}-p_{B}^{u}}{t}\right)
$$

and

$$
m_{B}^{u}=\frac{\alpha}{t}\left(p_{A}^{u}-p_{B}^{u}\right)+(1-\alpha)
$$

Firm $A$ 's and $B$ 's profits under uniform pricing are

$$
\pi_{A}^{u}=\alpha\left(p_{A}^{u}-c\right)\left(1-\frac{p_{A}^{u}-p_{B}^{u}}{t}\right)
$$




$$
\pi_{B}^{u}=\left(p_{B}^{u}-c\right)\left(\frac{\alpha}{t}\left(p_{A}^{u}-p_{B}^{u}\right)+(1-\alpha)\right)
$$

Setting the partial derivatives of the two profit functions equal to zero gives

$$
\frac{\partial \pi_{A}^{u}}{\partial p_{A}^{u}}=\alpha\left(1-\frac{p_{A}^{u}-p_{B}^{u}}{t}\right)-\frac{\alpha}{t}\left(p_{A}^{u}-c\right)=0
$$

and

$$
\frac{\partial \pi_{B}^{u}}{\partial p_{B}^{u}}=\frac{\alpha}{t}\left(p_{A}^{u}-p_{B}^{u}\right)+(1-\alpha)-\frac{\alpha}{t}\left(p_{B}^{u}-c\right)=0 .
$$

The following prices satisfy these equations and also satisfy the second-order conditions for profit maximisation:

$$
\begin{aligned}
& p_{A}^{u *}=c+\frac{1+\alpha}{3 \alpha} t, \\
& p_{B}^{u *}=c+\frac{2-\alpha}{3 \alpha} t .
\end{aligned}
$$

These prices are both at their highest when $\alpha=\frac{1}{2}$ (i.e., the firms have equal market shares), when the identical prices are $p_{A}^{u^{*}}=p_{B}^{u^{*}}=c+t$. Intuitively, the equal market shares mean that each firm's single price needs to give equal weight to exploiting existing customers and enticing its rival's customers, so price competition for new customers is muted. The prices are both at their lowest when $\alpha=1$ (i.e., firm $A$ had all the market in the previous period), when the prices are $p_{A}^{u^{*}}=c+\frac{2}{3} t$ and $p_{B}^{u^{*}}=c+\frac{1}{3} t$. Intuitively, firm $B$ now places full weight on enticing its rival's customers, so its price is lower.

In the above analysis we assumed that firm $A$ 's second-period price was higher, that is $p_{A}^{u} \geqslant p_{B}^{u^{*}}$. From the above solutions we can see that this will be true only if $\alpha \geqslant \frac{1}{2}$, that is firm $A$ has at least half the market. If we instead start from the converse assumption $p_{A}^{u}<p_{B}^{u^{*}}$, we obtain the solutions-

$$
\begin{aligned}
& p_{A}^{u}=c+\frac{1+\alpha}{3(1-\alpha)} t \\
& p_{B}^{u}=c+\frac{2-\alpha}{3(1-\alpha)} t
\end{aligned}
$$

From the form of these solutions, we can see that if $\alpha<\frac{1}{2}$, both firms' prices are at their lowest when $\alpha=0$ (this is symmetrical with the case of $\alpha=1$ above, except now firm $B$ rather than $A$ had all the market in the previous period). The lowest prices are $p_{A}^{u^{*}}=c+\frac{1}{3} t$ and $p_{B}^{u^{*}}=c+\frac{2}{3} t$, again symmetrical with the solutions for $\alpha \geqslant \frac{1}{2}$ above. 
Firm $A$ 's and firm $B$ 's equilibrium profits in the mature market under uniform pricing are

$$
\pi_{A}^{u *}=\frac{(1+\alpha)^{2}}{9 \alpha} t, \quad \pi_{B}^{u *}=\frac{(2-\alpha)^{2}}{9 \alpha} t, \quad \text { for } \alpha \geqslant \frac{1}{2}
$$

and

$$
\pi_{A}^{u *}=\frac{(1+\alpha)^{2}}{9(1-\alpha)} t, \quad \pi_{B}^{u *}=\frac{(2-\alpha)^{2}}{9(1-\alpha)} t, \quad \text { for } \alpha<\frac{1}{2} .
$$

Substituting the equilibrium prices (B.22) and (B.23) into (B.14) and (B.15), we see that the proportion of switching customers under uniform pricing is $(2 \alpha-1) / 3$ if $\alpha \geqslant \frac{1}{2}$, and $(1-2 \alpha) / 3$ if $\alpha<\frac{1}{2}$. Under paying customers to switch, the proportion of switchers was always $\frac{1}{3}$, which is higher than either of these expressions. Hence the deadweight loss from switching is higher under inertia pricing.

Industry profits

Comparing (B.12) and (B.13) with (B.24) and (B.25), we can see that industry profits when insurers practise inertia pricing are always lower than under uniform pricing.

\section{Consumer surplus}

Although industry profits are always lower under inertia pricing in this model, not all customers are better off. Under inertia pricing, the prices are given by equations (B.9) and (B.10): two-thirds of customers are stayers who pay $c+\frac{2}{3} t$ and one-third are switchers who pay $c+\frac{1}{3} t$, also incurring switching costs of up to $\frac{1}{3} t$ (because the switching costs are uniformly distributed on $[0, t]$ ). Under uniform pricing, the prices are given by equations (B.20) and (B.23): customers of the "weaker" firm with lower market share can obtain a price as low as $c+\frac{1}{3} t$ without the costs of switching.

However, for the special case where the firms have equal market shares, that is $\alpha=\frac{1}{2}$, under uniform pricing all customers pay $c+t$, which exceeds the highest price paid under inertia pricing $\left(c+\frac{2}{3} t\right)$ by more than the highest switching cost any customer who actually switches pays under inertia pricing $\left(\frac{1}{3} t\right)$. Thus where the firms have equal market shares, all customers are better off under inertia pricing than under uniform pricing.

\section{Market concentration}

Inertia pricing has implications for market concentration. The ability of rivals to "pay customers to switch" implies that this form of competition may make it more difficult for any one firm to maintain a large share of the market. This observation also suggests that the most enthusiastic proponents of inertia pricing should be new entrants, rather than incumbents with large market shares. This is reflected in the analysis above as follows: the prices under inertia pricing in equations (B.9) and (B.10) above are independent of market share, but those under uniform pricing in (B.20) to (B.23) depend on market share. 
More than two insurers

It can be shown that the above conclusions above a fortiori in a market with more than two firms. ${ }^{30}$ The intuition is that more firms means more competition for each customer's business, so that the payments made to customers to switch are further bid up, reducing prices and leaving firms in aggregate worse off. A larger number of competitors leads to a "winner's curse". 31

${ }^{30}$ Taylor (2003).

${ }^{31}$ Rothwell et al. (2009). 